\title{
Building a Courtyard-environment-monitoring System Based on Internet of Things Architecture
}

\author{
Wen-Tsai Sung ${ }^{1}$ and Sung-Jung Hsiao ${ }^{2 *}$ \\ ${ }^{1}$ Department of Electrical Engineering, National Chin-Yi University of Technology, \\ No. 57, Sec. 2, Zhongshan Rd., Taiping Dist., Taichung 411030, Taiwan \\ ${ }^{2}$ Department of Information Technology, Takming University of Science and Technology, \\ No. 56, Sec. 1, Huanshan Rd., Neihu District, Taipei City 11451, Taiwan
}

(Received February 24, 2021; accepted July 7, 2021)

Keywords: Internet of Things, wireless network, intelligent control, fuzzy control

With the rapid development of technology, people are living a faster pace of life as they seek a better quality of life, and this has led to various stresses. Horticultural therapy and city greenification have emerged in recent years as countermeasures to relieve the stresses of a busy life by using plants to beautify the townscape. In this study, we used NodeMCU as a master control board and sensing modules to detect the temperature, humidity, illuminance, soil moisture, and rain in a courtyard environment. An ESP8266 Wi-Fi chip was used for the wireless transmission of data and the control of loads of sprinklers, fans, plant lights, landscape lamps, and step motors for awnings to implement the system, which was based on the concept of the Internet of Things (IoT). This system uses fuzzy control for automatic control and sets up a rule base in accordance with the effects of current air humidity, temperature, and soil moisture on the plants in the courtyard to control the sprinklers, fans, and plant lights to make the environment suitable for plants. The automatic control and network techniques are expected to enable people to enjoy horticulture from their homes without any additional burden.

\section{Introduction}

Life pressure and mental emotions have an inextricable relationship. Symptoms such as anxiety, depression, headaches, and insomnia have become common in modern lives. From the viewpoint of psychotherapy, these symptoms are actually symptoms of "neurosis disorder".(1) Moreover, because many people find it difficult to accept that they suffer from mental illness, they miss the optimal period for treatment, increasing the difficulty of treatment.

Neurosis disorder is a common mental illness. Studies show that the prevalence of mental illness in a lifetime is about 20 to $50 \%$, but many people struggle with their condition without seeking treatment. The causes of mental illness are diverse and must be carefully assessed simultaneously by a psychiatrist at the psychological, physiological, social, and other levels, and patients may be required to take psychotherapy drugs supplemented by psychological and behavioral treatments. ${ }^{(2)}$

*Corresponding author: e-mail: sungjung@gs.takming.edu.tw https://doi.org/10.18494/SAM.2021.3343 
Numerous studies, including those by the American Horticultural Therapy Association in 1973 and the Taiwan Horticultural Therapy Association in 2013, have confirmed the effects of plants in alleviating the psychological stresses of the body and mind. An occupational therapist at Shuang Ho Hospital said that gardening can stimulate the five senses, and daily exposure to plants can reduce stress. ${ }^{(3)}$ Exposure to plants has also been shown to lead to significant improvements in perception, cognitive, and social interaction skills for people with dementia, autism, and intellectual disabilities. ${ }^{(4)}$

The benefits of plants in terms of the human body are roughly divided into three types. The first is that plants can stimulate the senses of the body, and the body and mind can be restored by contact with plants. The second is that humans feel a sense of responsibility for the lives of plants, believing that plants must be nurtured to grow. The third is that the beauty of plants themselves is considered to be have a positive effect on the human body. ${ }^{(5,6)}$ It has also been pointed out that in the physiological metabolic process of plants, in addition to the release of photosynthesis by-products such as oxygen, there are other components beneficial to the human body, mainly volatile compounds such as terpenes, alcohols, aldehydes, fatty acids, and other derivatives, which can be obtained by concentrating the extracts of flowers and herbs into essential oils. ${ }^{(6)}$ These can be used in applications such as common aromatherapy to relieve the symptoms of physical and mental discomfort, because in the nervous system, smell and mood are closely linked to each other. Odors are transmitted to the limbic system, which controls memory and emotional response, so growing scented plants can have significant benefits in improving mood and relieving stress. ${ }^{(7)}$

In pursuit of a more convenient lifestyle and a higher quality of life, in addition to promoting the well-known intelligent home monitoring technology, many homes now also have green courtyards or small personal farms on rooftops and in outdoor spaces. Some local governments now require construction sites to have green walls to beautify the city and add some greenery to the concrete jungle, enabling people to take a breather from their busy urban lives. Unfortunately, for people with reduced mobility, busy lives, or little experience with horticulture, although greenery can be enjoyed, owning a courtyard or small farm can be unrealistic. However, if the Internet of Things (IoT) technology can be applied to a yard or small farm, ${ }^{(8)}$ people may be able to enjoy greenery and harvest crops with little effort.

Wireless networks are becoming more common. Research in this field is based on the architecture of the IoT, where multiple sensing modules are set up in the perception layer to connect to the NodeMCU1 transmitter. ${ }^{(9)}$ Our courtyard-environment-monitoring system is used to monitor various environmental parameters. Wireless signals are sent to the NodeMCU1 transmitter, which transmits them to the ThingSpeak platform. At the system application layer, the NodeMCU2 receiver reads the data in the ThingSpeak platform and sends it to the user interface. When the environmental data does not match the threshold set by the user, the system will automatically control the environmental change device by calculating the most appropriate decision based on the setting of the rule base in fuzzy theory, thus realizing automated environmental monitoring. In addition, there is a manual control switch in the mobile app, and the manual control mode can be turned on as required. 


\section{Literature Discussion}

\subsection{IoT}

Bill Gates first mentioned the concept of the IoT in his book The Road Ahead in 1995, although it attracted little public attention because of the need for the development of networks, hardware, and sensing devices. With advances in technology, the International Telecommunication Union formally introduced the concept of the IoT in 2005, and in his inaugural address in 2009, U.S. President Barack Obama responded positively to the "smart planet" proposed by IBM Corporation. Since then, the IoT has attracted widespread attention. ${ }^{(10)}$

The IoT system architecture is constructed from the bottom up, as shown in Fig. 1, and is divided into three layers, namely, the perception layer, the network layer, and the application layer, each of which is connected to the other two, although this is just one of the ways of dividing up the IoT architecture.

The IoT can be regarded as a dynamic global network infrastructure. The IoT is known as the third wave of the development of the world's information industry after computers and the Internet, realized through the integrated applications of perception, recognition, and computing. The IoT has a wide range of uses. It can even be considered to cover almost all parts of people's lives, from smart houses, smart transportation, and even environmental monitoring to medical networking and other fields.

People often mistake the IoT as an infinite extension of a network and think that the IoT is a fully shared, ubiquitous network platform; thus, they identify the IoT as a hard-to-implement technology. ${ }^{(11)}$ The definition of the IoT is very simple: all items are connected through radiofrequency identification and other information-sensing devices in series for intelligent identification and management. The IoT must have the following characteristics: ${ }^{(12)}$

i. Dedicated network architecture

The IoT is widely used and has different needs for different types of data transmission, so a dedicated network architecture is required for different applications. Therefore, the system will not impose an excessive load on a single network.

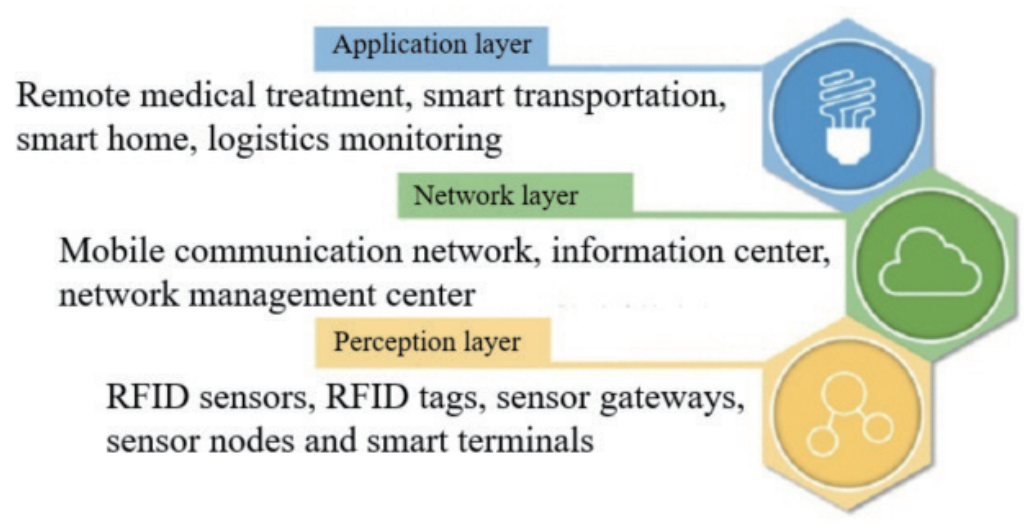

Fig. 1. (Color online) IoT architecture. 
ii. Real-time response speed

The IoT is generally used in real-time monitoring and management, and failure to process data properly in real time can cause significant losses.

iii. Large amounts of data in different patterns must be processed

As mentioned in the first two points, the IoT is very large because of its wide range of applications and the need for real-time monitoring; thus, it must be able to handle large amounts and different patterns of data.

iv. Analysis and optimization capabilities

When the data processing speed is not sufficiently high, the data is optimized, an extra processing space is extracted, and intelligent spatial allocation is performed to enable the IoT to transmit the data more stably.

\subsubsection{Perception layer}

The perception layer, which is like a human terminal nerve, is used to identify and sense the environmental information. This layer is the first layer of the IoT architecture and is the most basic and important layer. It has a low-frequency bandwidth and low power consumption, and can support multiple sensors. The perception layer includes sensing devices, a local network for transmitting sensing data, and a gateway connecting the network. The sensing module senses surrounding environmental data, such as the light intensity of the environment, the rotation speed of the fan blades, the temperature of the courtyard garden, the humidity of the courtyard garden, the concentration of carbon monoxide in the courtyard garden, and the concentration of carbon dioxide in the courtyard garden. The sensing module regularly sends data to the gateway, then the signal is converted and sent to the network layer.

The network transmission of the sensing area includes a wired network and a wireless network. A wired area network is adopted in applications such as factory automation, medical instruments, and energy management. Wireless regional networks are used for moving objects. A wireless network is used in applications such as smart vehicles, radar, and communications. ${ }^{(13)}$

\subsubsection{Network layer}

The network layer, which is like the central nerve of the human body, connects the perception layer with the application layer, connects wired and wireless networks, and is responsible for the centralized transformation of the sensed information and the transmission of the information to the application layer. If the range of objects to be measured is not fixed or objects are moving, or if the network is used in outdoor environments, the range of transmission is expanded usually by using the Internet, cable television networks, and telecommunications networks, or, alternatively, through Wi-Fi or internal cable networks.

When the network scale is expanded to the IoT, the number of terminal network nodes may surge, giving rise to the problem of network management, whereby IP addresses must be redistributed. As more enterprises have been established, the IoT has become more efficient and more convenient to control. Taiwan's IPv4 addresses will face the problem of exhaustion, but 
some experts believe that through the establishment of IDs to identify the sensing nodes, as well as the establishment of virtual IP addresses, the consumption of physical IP addresses may be reduced. ${ }^{(13)}$

\subsubsection{Application layer}

The information from the perception layer is transmitted to the application layer through the network layer, which, in addition to automatic recognition, performs further analysis and calculation of the information, automatically processes it to obtain specific data, and makes decisions. However, the effect of a single message on the entire system of the IoT is insignificant, so the function of the application layer is to link the information from each node and to evaluate the position and significance of each piece of information. Therefore, it is necessary to connect and integrate the data sensed by multiple sensing systems, enable the automatic processing of the system, and perform a large number of data analyses.

The technologies of cloud computing are helpful in expanding the scale and application of the IoT. One of the more important technologies is distributed operations of big data analytics, such as Hadoop. In fact, the IoT data content is more than a single piece of data but is not complex. However, because it is real-time data, long-term accumulation leads to an enormous amount of data necessitating a phenomenal amount of computing. Consequently, the system uses parallel computing technology in which the data is divided into multiple units and sent to multiple servers, where each server performs its assigned work in concert with the other servers. Finally, all the servers return the results of the operation to the system, thereby accelerating the processing of the enormous amount of data. ${ }^{(13)}$

\subsection{ESP8266 chip}

The master version of NodeMCU used in this study comprises a development board made by Ai-Thinker based on the Espressif ESP8266 ESP-12E module, which is referred to here as the ESP8266 chip. The ESP8266 chip is a 32 bit single-chip microprocessor developed by Shanghai Lexin Company, integrating a Wi-Fi chip supporting IEEE $802.1 \mathrm{lb} / \mathrm{g} / \mathrm{n}$, which can support an Arduino peripheral sensing module because it is compatible with Arduino peripheral pins. The ESP8266 chip can be used in a wide range of applications, such as home appliance monitoring, remote monitoring, and cloud databases, making it suitable for the IoT. The IEEE $802.11 \mathrm{~b} / \mathrm{g} / \mathrm{n}$ wireless network standards are shown in Table 1. The ESP8266 chip with the following specifications is shown in Fig. 2.

Table 1

Wireless network standards of IEEE 802.11.

\begin{tabular}{|c|c|c|c|c|}
\hline \multicolumn{2}{|l|}{ Item } & IEEE $802.11 \mathrm{~b}$ & IEEE $802.11 \mathrm{~g}$ & IEEE $802.11 \mathrm{n}$ \\
\hline \multicolumn{2}{|c|}{ Frequency } & $2.4 \mathrm{GHz}$ & $2.4 \mathrm{GHz}$ & $2.4 \mathrm{GHz}$ \\
\hline \multicolumn{2}{|c|}{ Transfer speed } & 1-11 Mbps & 6-54 Mbps & 7.2-72.2 Mbps \\
\hline \multirow{2}{*}{ Range } & Indoor & $35 \mathrm{~m}$ & $38 \mathrm{~m}$ & $70 \mathrm{~m}$ \\
\hline & Outdoor & $140 \mathrm{~m}$ & $140 \mathrm{~m}$ & $250 \mathrm{~m}$ \\
\hline
\end{tabular}




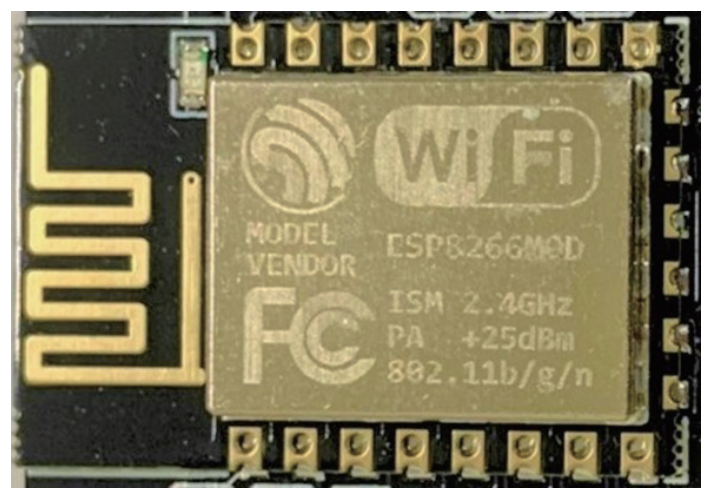

Fig. 2. (Color online) ESP89266 chip.

1. The input power supply is $3.3 \mathrm{~V}$ and the current is $215 \mathrm{~mA}$.

2. The ESP8266 processor is based on the Tensilica Xtensa Diamond Standard.

3. The ROM/RAM provides $64 \mathrm{~K}$ boot ROM, $64 \mathrm{~K}$ instruction RAM, and more than $94 \mathrm{~K}$ data RAM.

4. Flash memory is expanded to $4 \mathrm{MB}$ and can be used to store real-time operating systems and applications.

5. Wi-Fi $802.11 \mathrm{~b} / \mathrm{g} / \mathrm{n} 2.4 \mathrm{GHz}$ radio can be set to AP, Station, or Station+AP and various network application modes.

6. This module additionally provides functions including a timer, deep sleep mode, and JTAG debugging.

7. Thirteen GPIOs support PWM, I.2C, UART, SPI, and a 10 bit ADC peripheral function. There is no DAC function.

\subsection{Wi-Fi}

Wi-Fi is a registered trademark of the Wireless Ethernet Compatibility Alliance (WECA, renamed Wi-Fi Alliance in 2002) and, in China, indicates wireless compatibility. Wi-Fi is the common term for a wireless regional network based on the IEEE802.11 standard, also known as a wireless network. Usually connected to a telecommunications network, cables must be connected to each other via nodes. There are many types of transmission medium used, which can be broadly divided into light and radio waves, as shown in Table 2 . The greatest disadvantage

Table 2

Wireless area network media classification.

\begin{tabular}{lc}
\hline Optical & $\begin{array}{c}\text { Infrared } \\
\text { Laser }\end{array}$ \\
\hline \multirow{3}{*}{ Radio waves } & DSSS \\
& FHSS \\
& HomeRF, HyperLan \\
Bluetooth
\end{tabular}


of light waves as a medium is that transmission can be interrupted when they encounter obstacles, whereas radio waves do not have this problem.

Wireless networks can be divided into local area networks (LANs) and wide area networks (WANs) by the data network transmission distance. Wireless LAN is dominated by the IEEE 802.11 standard, U-NII was established by the Federal Communications Commission (FCC) in the United States, and high-performance radio LAN (HiperLAN) was developed by the European Telecommunications Standards Institute (ETSI) in Europe. Wireless WANs are also known as mobile data networks and include mobile phones, radio systems, wireless data transfer, and personal communications services. ${ }^{(14)}$

Most wireless networks use low-frequency electromagnetic waves as the transmission medium, because such waves enable all-round transmission and their penetration is strong and not limited to a specific direction, making them especially suitable for LANs. The disadvantage of high-frequency light waves (infrared, laser) is that the path of travel must be straight, and most obstacles cannot be penetrated without producing refraction and scattering phenomena. ${ }^{(15)}$

Wi-Fi is a major advantage because it does not require wiring and is not limited by terrain conditions, and Wi-Fi radio waves cover a wide range of about $100 \mathrm{~m}$. In the past, Bluetooth wireless transmission was used, but its range is limited to within a classroom. In contrast, the transmission range of Wi-Fi is the entire building. VIVATO Technologies Co. produced a new networking device that extends the original $100 \mathrm{~m}$ transmission distance of Wi-Fi to $6.5 \mathrm{~km}$. The Wi-Fi approach uses refraction and scattering. ${ }^{(16)}$

\subsection{Plant growth elements}

As shown in Fig. 3, five elements are essential to plant growth: light, temperature, air humidity, soil moisture, and air quality. In this study, we aim to use sensing modules and automatic load control monitoring to create an environment in which plants grow and thrive with little human input.

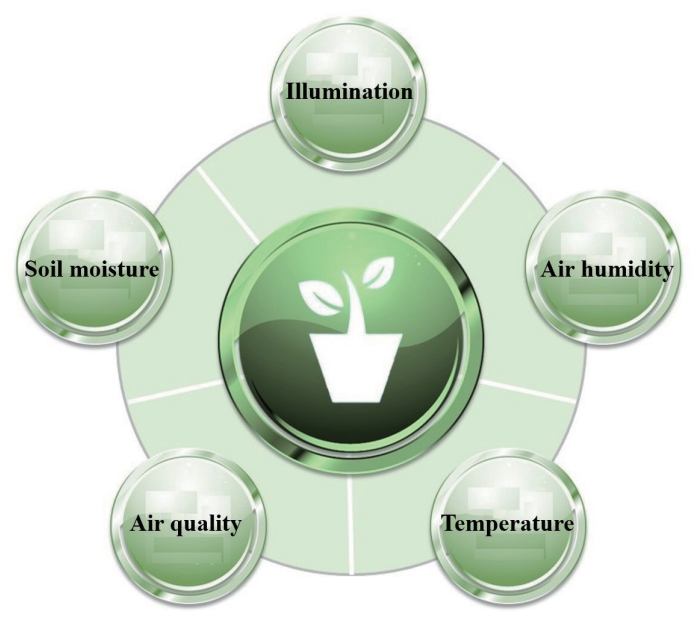

Fig. 3. (Color online) Five elements of plant growth. 


\section{System Architecture and Hardware Devices}

On the basis of the IoT concept, we divide our system into four parts: the perception layer, the application layer, the network layer, and the terminal monitoring device. The architecture and block diagram of the system functions are shown in Figs. 4 and 5, respectively. The perception layer concerns the plant growth factors and consists of four sensing modules: the temperature and humidity sensing module, the photoresistor module, the soil moisture sensing module, and

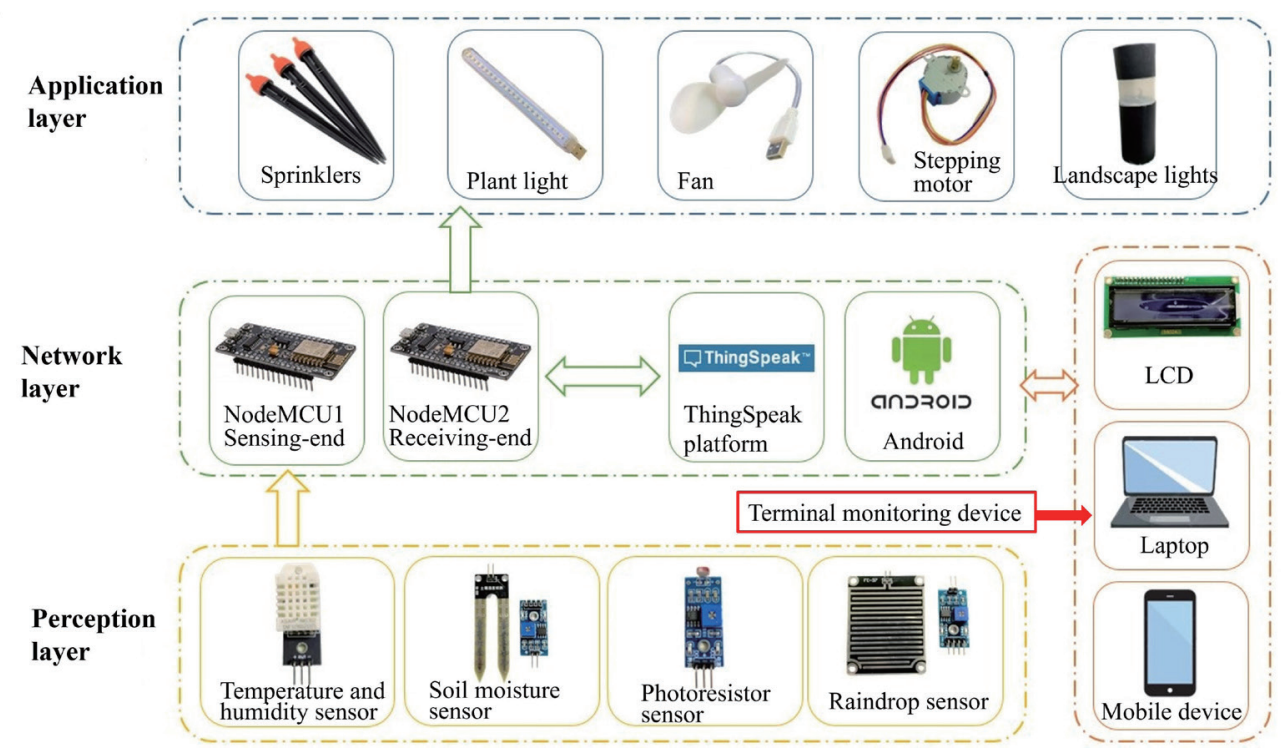

Fig. 4. (Color online) System architecture.

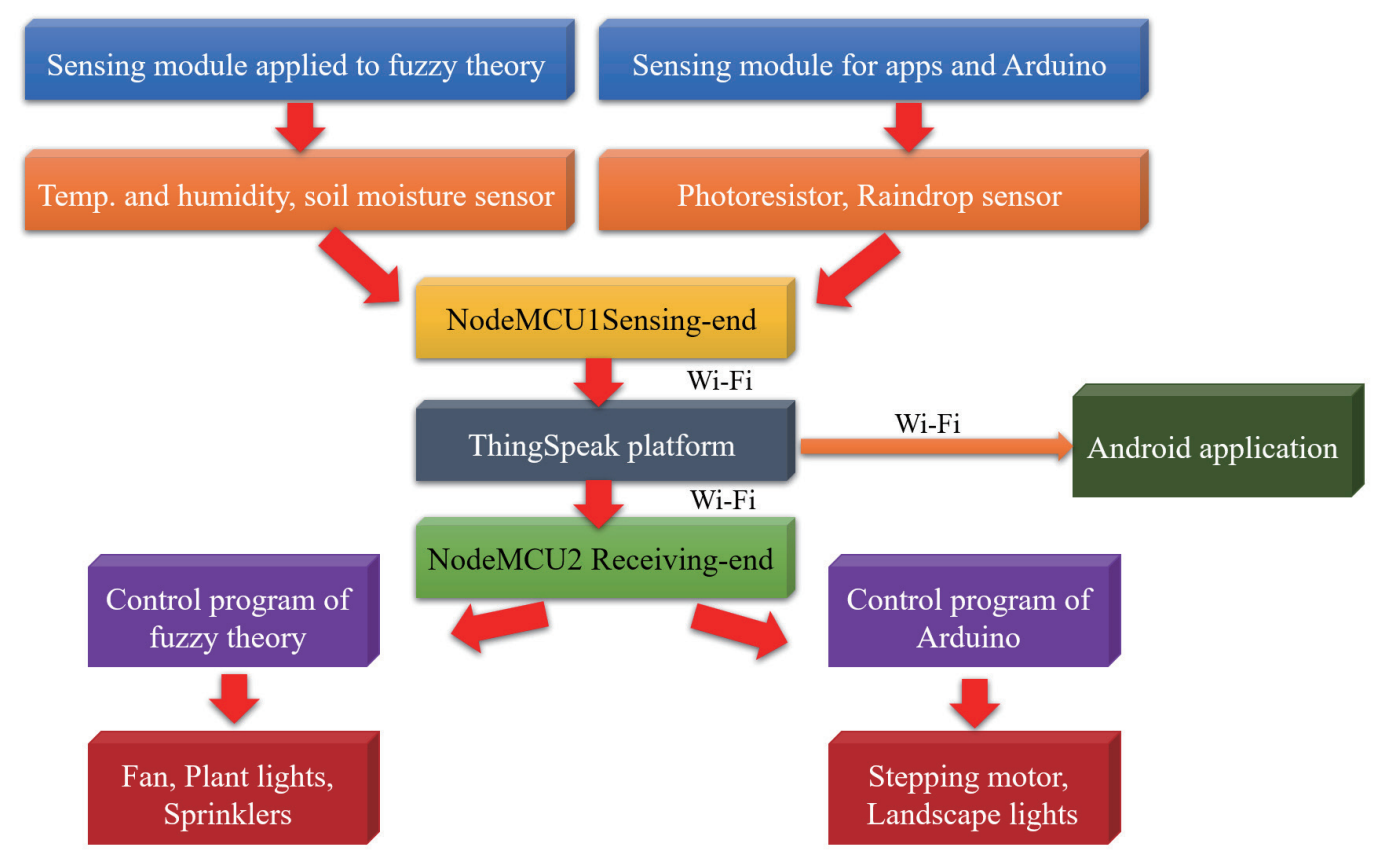

Fig. 5. (Color online) Block diagram of system functions. 
the raindrop sensing module. Five devices are set up in the application layer: sprinklers, plant lamps, landscape lamps, stepping motors, and canopy. The positions of sensing modules and devices are shown in Figs. 6 and 7, respectively.

Figure 8 shows the flowchart of environment sensing by the system. After the system is started, the sensor modules start to sense the environmental values, which are sent to the NodeMCU sensor terminal. The LCD module displays the ambient temperature, humidity, soil status, and weather (sunny or rainy) status, so that the user can monitor the courtyard environment. The sensed environmental values are uploaded to the ThingSpeak platform via the ESP8266 Wi-Fi chip, and the data is simultaneously stored in the cloud.

Figure 9 shows the flowchart of environment control by the system. The NodeMCU receiver reads the environment values in the ThingSpeak platform. The user can set different temperature,

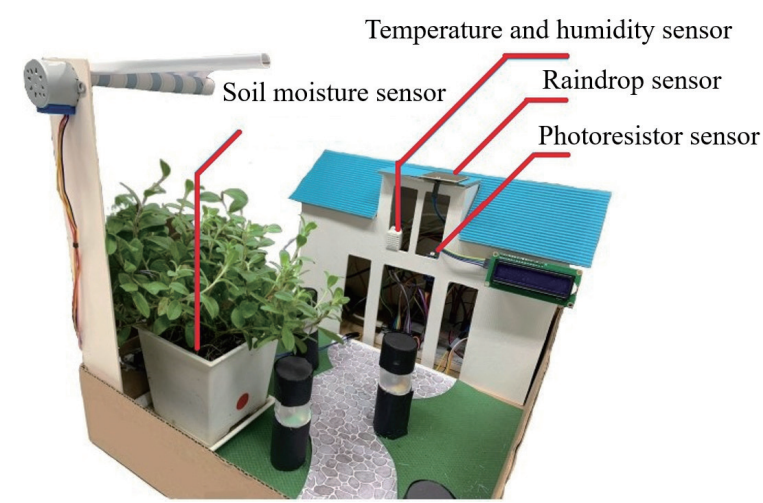

Fig. 6. (Color online) Positions of sensing modules.

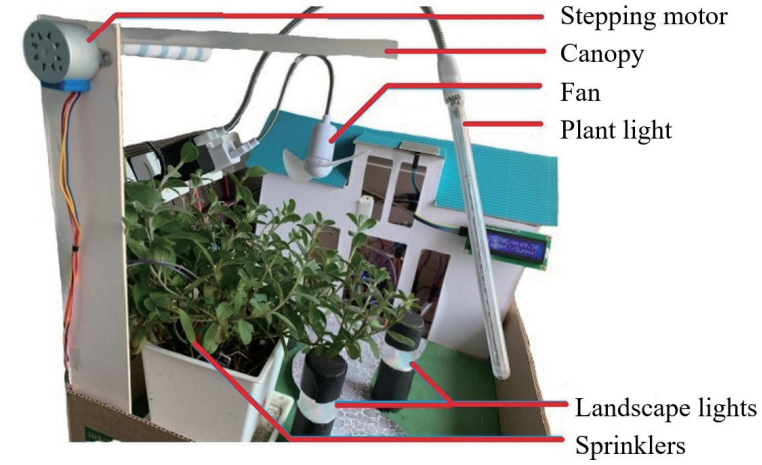

Fig. 7. (Color online) Various positions of the controlled hardware devices used in this paper.

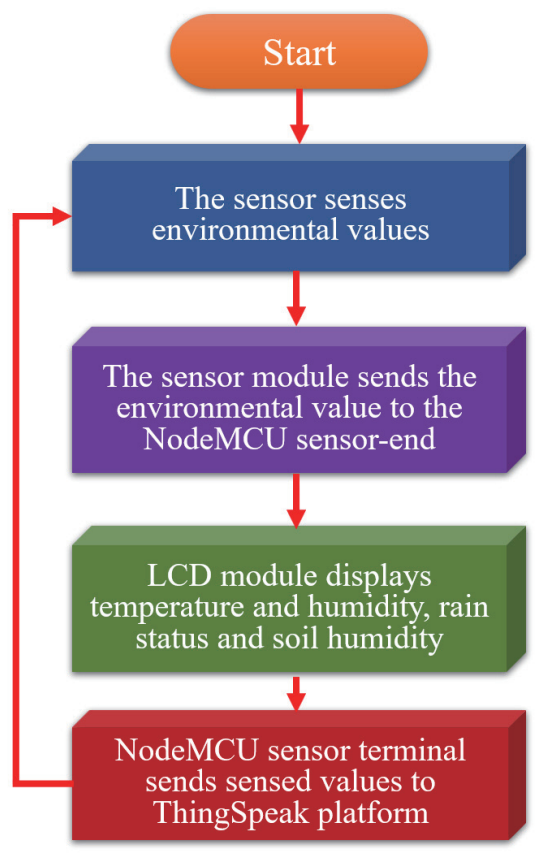

Fig. 8. (Color online) Flowchart of environment sensing by the system. 


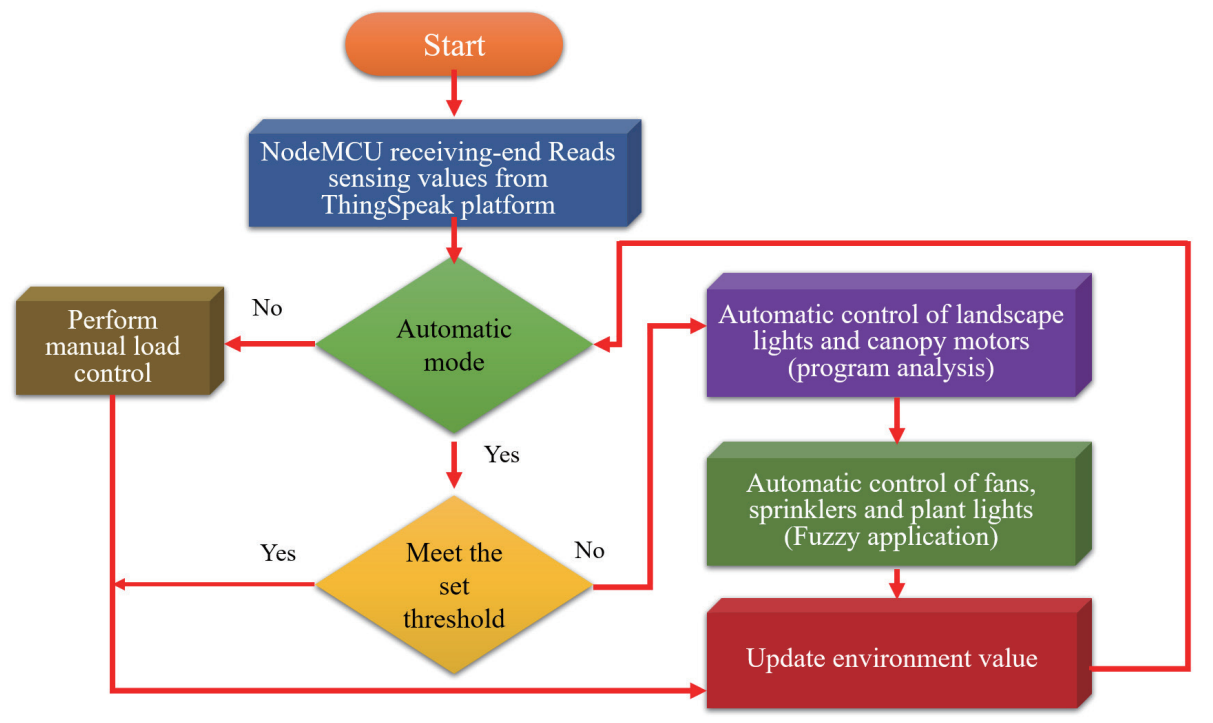

Fig. 9. (Color online) Flowchart of automatic environment control by the system.

humidity, and soil humidity thresholds in accordance with the growth environment required by the plant. First, the system determines its operational mode. In the manual mode, the user controls the load. In the automatic mode, the system analyzes the environmental values of each chart on the platform. If the environmental data does not match the thresholds set by the user, this system activates the appropriate control device. Then, using fuzzy control, the system starts the load in accordance with the program setting. For example, when the raindrop sensor module senses raindrops, the stepping motor is activated to extend the canopy, and when the photoresistor module cannot sense light, plant lights are turned on. The values of the temperature, humidity, and soil moisture are used in the proposed fuzzy theory to calculate the most favorable conditions for plants, and the various devices, such as sprinklers, fans, and plant lights, are automatically controlled to maintain suitable environmental parameters in the courtyard. Users can use mobile devices such as mobile phones, tablets, or computers to monitor the data on the ThingSpeak platform and inform themselves of the environment of the courtyard. They can also use the Android mobile application to monitor the data in real time. If necessary, they can switch the system to the manual mode and use the mobile device to control the load devices. In this manner, the remote monitoring of the environment is achieved.

NodeMCU combined with ESP8266 and CP2102 chips supports the USB power supply; has a port drive capacity of $15 \mathrm{~mA}$; comprises Wi-Fi, GPIO, PWM, ADC, I2C, 1-Wire, and other functions on a one-body control board; and has a processing speed of $80 \mathrm{MHz}, 64 \mathrm{~K} \mathrm{ROM}$ and RAM, 13 GPIO feet at the positions shown in Fig. 10, an operating voltage of 4.5 to $9 \mathrm{~V}$, and an operating temperature between -40 and $125{ }^{\circ} \mathrm{C}$. The developed board is shown in Fig. 11. The left half of the raised PCB is the ESP8266 module, and the right half of the USC chip (CP2102 chip) contains the slots, reset, and other components.

In order for the input parameters and output load to affect each other, it is necessary to use the multi-input multi-output (MIMO) mathematical model. In this study, fuzzy theory is selected for control. The input is based on the reference documents of plants to set attribution functions, 


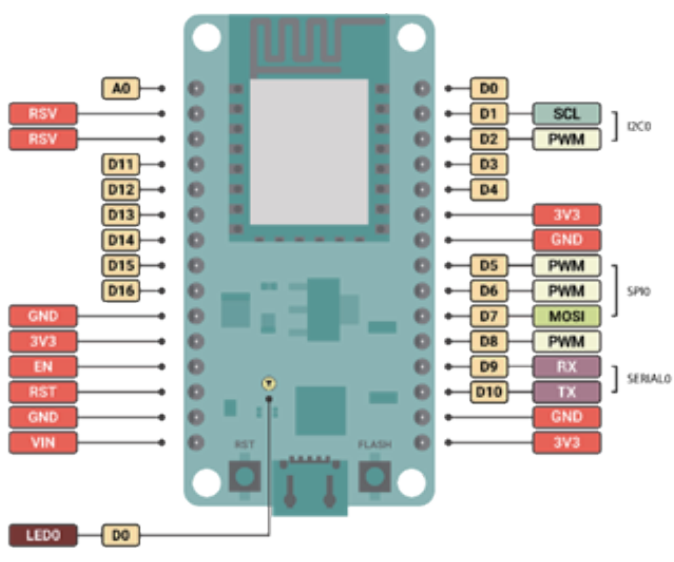

Fig. 10. (Color online) Pin map of NodeMCU.

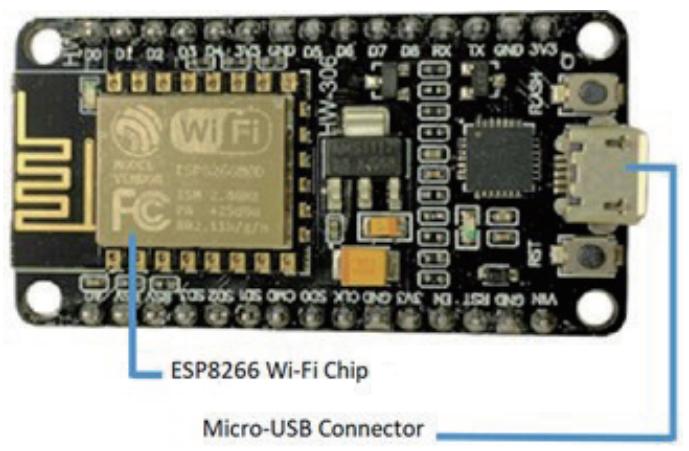

Fig. 11. (Color online) NodeMCU module.

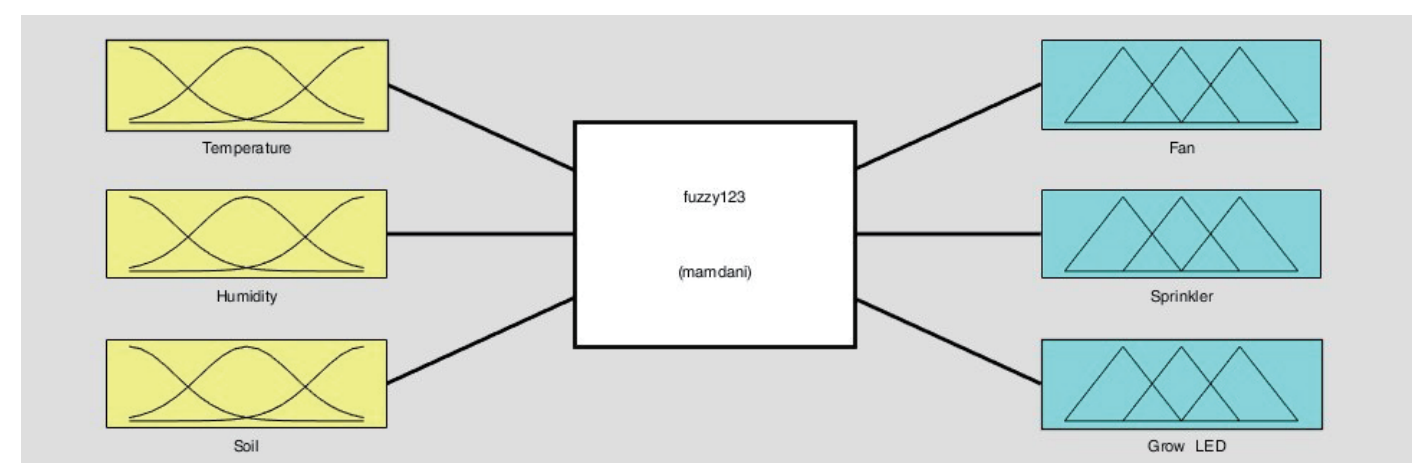

Fig. 12. (Color online) Architecture of fuzzy control.

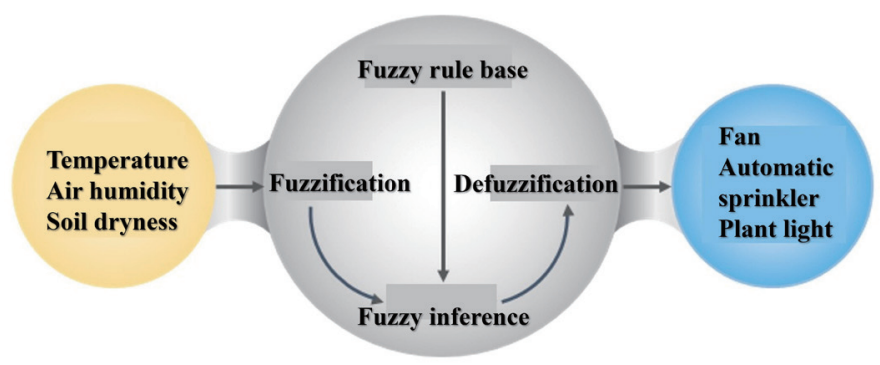

Fig. 13. (Color online) Flowchart of fuzzy control.

then, on the basis of the above considerations, the load that can improve the environmental parameters is selected for output control. The architecture and process of fuzzy control are respectively shown in Figs. 12 and 13.

The rule base of this system is set up using references related to E. nuttallianus and has been discussed with gardening experts with many years of experience. E. nuttallianus is a species of flowering plant in the morning glory family with the common name of shaggy dwarf morning glory. This rule base is expected to be used with fuzzy theory to control nonlinear environmental parameters; thus, it makes the courtyard environment more stable and suitable for plant growth, as shown in Fig. 14. 


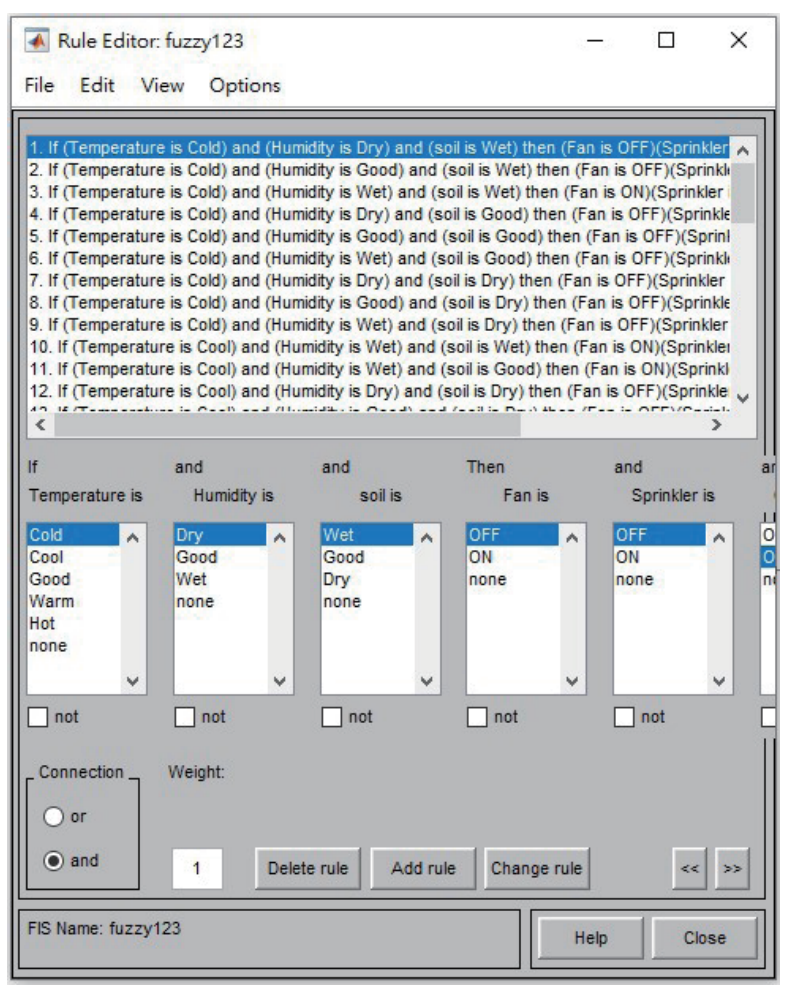

Fig. 14. (Color online) Setting of the fuzzy theory rule base.

The fuzzy inference system simulates people's decisions about the current environmental state on the basis of the settings of the rule base. For example, as shown in Fig. 15, when the ambient temperature is $30{ }^{\circ} \mathrm{C}$, the air humidity is $80 \%$, the soil dryness is 980 , and the surface soil is dry, the decision made by fuzzy inference is to turn on the fan and sprinkler to reduce air humidity by providing air convection and increase soil humidity by providing water through sprinklers.

\section{System Architecture and Hardware Devices}

ThingSpeak is a free application platform designed specifically for the IoT, as shown in Fig. 16. Each channel in the platform has a different ID that determines whether the channel is public or private. On the other hand, an original IoT remote monitoring platform can be created in accordance with the number of new charts required. In this study, two NodeMCUs were used as wireless transmission upload and read control boards. Wi-Fi chips in NodeMCU on the sensing and receiving sides wirelessly upload data to the ThingSpeak platform via the unique Write API Key and Read API Key, respectively, and read the data in the platform, allowing users to monitor the state of the courtyard environment from the line charts of the data in the platform, as shown in Fig. 17.

As shown in Fig. 11, using the Arduino program to set the Wi-Fi name, password, and API key to be connected at the NodeMCU sensor, one can connect to the corresponding ThingSpeak platform, the data to be displayed in the chart is set up in sequence, and the data in the platform 


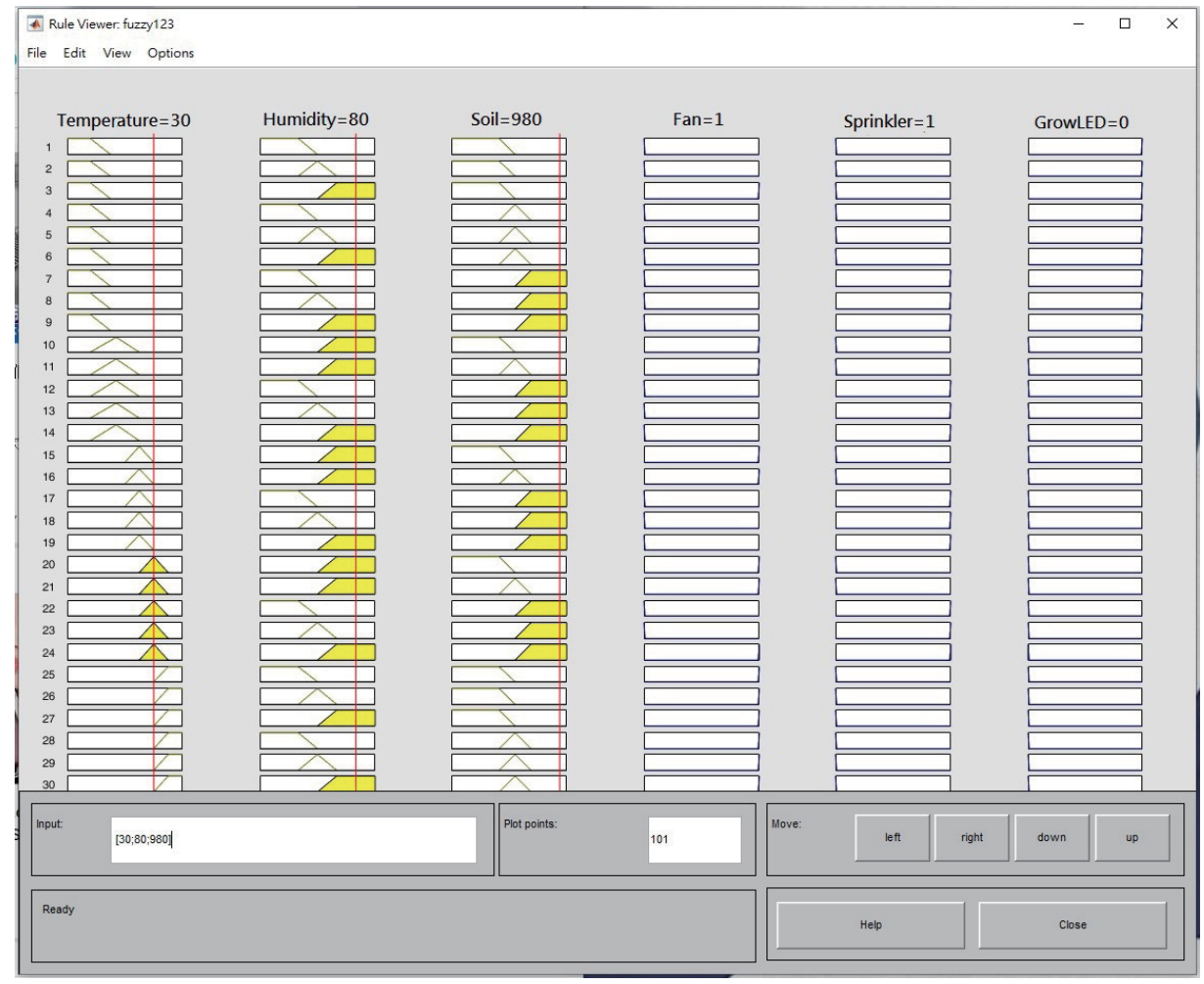

Fig. 15. (Color online) Fuzzy inference.

\section{$\square$ ThingSpeak" channels - Apps - Supportr- Commercial Use How to Buy HL}

\section{Courtyard Environmental Monitoring System}

Channel ID: 950945

Author: mwa0000017188300

Access: Public

Private View Public View Channel Settings Sharing API Keys Data Import/Export

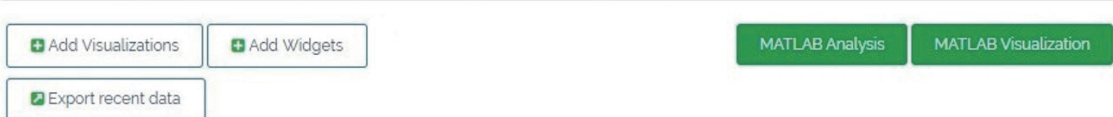

Channel Stats

Created: 5 months ago

Lastentry: 27 days.age

Fig. 16. (Color online) ThingSpeak platform interface.

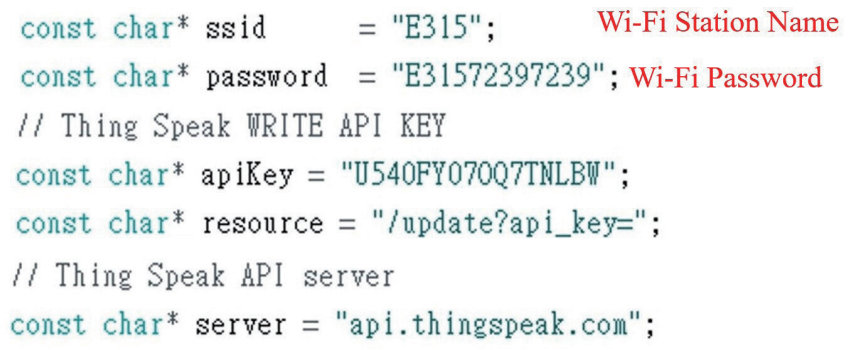

Fig. 17. (Color online) The sensing end NodeMCU is connected to the Settings program of ThingSpeak. 
can be monitored remotely. The NodeMCU receiver reads the value in much the same way as on the sensing side except that instead of the Write API Key, the Read API Key is used, which sets the chart to read in sequence. The data of each chart in the channel can be viewed to confirm that the data has been read correctly. The Arduino program can be used to display the read value to confirm that the data corresponds to the relevant chart.

The system in this study uses Wi-Fi wireless communication protocol as the method of data transmission. Generally, the wireless transmission distance of the system using Wi-Fi is about $100 \mathrm{~m}$. In our actual environment, the transmission distance of Wi-Fi protocol does not exceed $100 \mathrm{~m}$.

\section{Experimental Analysis and Data Comparison}

The main function of this system is to maintain appropriate conditions in the plant growth environment conducive to the healthy growth of plants under various weather conditions. First, pots of E. nuttallianus were purchased from a nursery that specializes in selling plants, and the purchased E. nuttallianus plants were divided into two pots to ensure that all specimens grew in soil with the same nutrients before the experiment. In this experiment, the specimens were placed on two adjacent windowsills. One pot grew in an uncontrolled natural environment while the other pot grew in an environment where the temperature, air humidity, and soil humidity values were updated every $30 \mathrm{~min}$ for use in fuzzy control. Note that, because the effect of the outdoor environment on plants and the monitoring of data are the main concerns in this research, we do not study indoor landscaping plants.

\subsection{Continuous rain for many days}

Figure 18 shows the environmental values sensed under continuous rain for many days. From May 16 to May 22, 2020, thunderstorms occurred continuously and the average temperature was $28{ }^{\circ} \mathrm{C}$. The main effect of rainy days on plants was extremely high air humidity, which results in low evapotranspiration efficiency, and the rain caused the soil moisture to be very high.

Because of the continuous rain for many days, the soil was kept moist. By considering the 15:25 sensing data as an example, the temperature was determined to be $26.5^{\circ} \mathrm{C}$, the humidity $89 \%$, and the soil moisture 352 , which means that the soil was very wet. The results of fuzzy inference are shown in Fig. 19. To reduce air humidity, the fan was activated to produce air convection. The sprinkler was not activated because of the high soil humidity, but because the air and soil humidities were higher than the threshold values, the plant lights were activated to improve evapotranspiration.

Without fuzzy control, the highest temperature is $27.2^{\circ} \mathrm{C}$, the lowest temperature is $24.1^{\circ} \mathrm{C}$, and the average temperature is $25.6^{\circ} \mathrm{C}$; with fuzzy control, the highest temperature is $26.1^{\circ} \mathrm{C}$, the lowest temperature is $24.7^{\circ} \mathrm{C}$, and the average temperature is $25.3^{\circ} \mathrm{C}$. It can be seen from Fig. 20 that smaller changes are observed for fuzzy control (blue curve).

Without fuzzy control, the highest humidity is $93 \%$, the lowest humidity is $67 \%$, and the average humidity is $83.8 \%$; with fuzzy control, the highest humidity is $79 \%$, the lowest humidity 


\begin{tabular}{|c|c|c|c|c|c|c|}
\hline \multicolumn{5}{|c|}{ Use fuzzy control } & \multicolumn{5}{l|}{ General control } \\
\hline Time & Temp. $\left({ }^{\circ} \mathrm{C}\right)$ & Airhumidity $(\%)$ & Soil moisture & Temp. $\left({ }^{\circ} \mathrm{C}\right)$ & Airhumidity(\%) & Soil moisture \\
\hline $2020 / 5 / 1912: 25$ & 24.9 & 72 & 676 & 25.5 & 73 & 672 \\
\hline $2020 / 5 / 1912: 55$ & 25.3 & 66 & 697 & 26.2 & 68 & 602 \\
\hline $2020 / 5 / 1913: 25$ & 25.6 & 70 & 666 & 25.7 & 70 & 562 \\
\hline $2020 / 5 / 1913: 55$ & 25.3 & 70 & 757 & 25.5 & 71 & 576 \\
\hline $2020 / 5 / 1914: 25$ & 25.4 & 63 & 742 & 25.6 & 67 & 489 \\
\hline $2020 / 5 / 1914: 55$ & 26.1 & 75 & 638 & 27.2 & 85 & 374 \\
\hline $2020 / 5 / 1915: 25$ & 25.8 & 76 & 725 & 26.5 & 89 & 352 \\
\hline $2020 / 5 / 1915: 55$ & 25.7 & 79 & 720 & 26.5 & 91 & 358 \\
\hline $2020 / 5 / 1916: 25$ & 25.3 & 69 & 712 & 25.9 & 84 & 259 \\
\hline $2020 / 5 / 1916: 55$ & 25.6 & 74 & 686 & 25.6 & 90 & 247 \\
\hline $2020 / 5 / 1917: 25$ & 25.7 & 75 & 752 & 25.9 & 91 & 243 \\
\hline $2020 / 5 / 1917: 55$ & 25.1 & 74 & 766 & 24.3 & 89 & 368 \\
\hline $2020 / 5 / 1918: 25$ & 24.8 & 75 & 724 & 24.7 & 93 & 371 \\
\hline $2020 / 5 / 1918: 55$ & 25.2 & 75 & 668 & 25.3 & 91 & 368 \\
\hline $2020 / 5 / 1919: 25$ & 25.1 & 76 & 669 & 24.7 & 91 & 347 \\
\hline $2020 / 5 / 1919: 55$ & 25.1 & 77 & 698 & 25.2 & 92 & 353 \\
\hline $2020 / 5 / 1920: 25$ & 24.7 & 78 & 765 & 24.1 & 93 & 328 \\
\hline
\end{tabular}

Fig. 18. (Color online) Environmental data with and without fuzzy control.

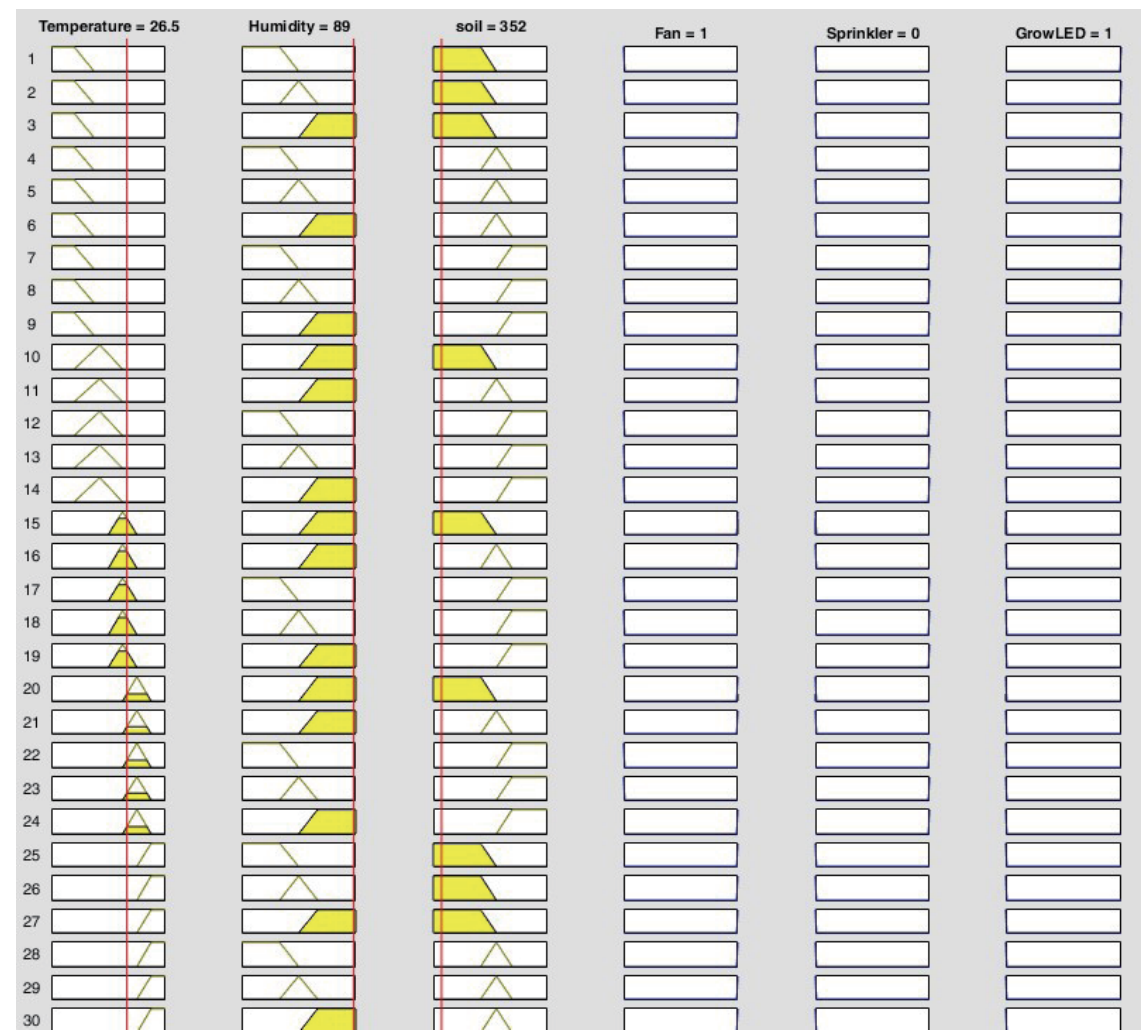

Fig. 19. (Color online) Results of fuzzy inference using data of 2020/5/19 15:25.

is $63 \%$, and the average humidity is $75.5 \%$. It can be seen from Fig. 21 that smaller changes are again observed for fuzzy control (blue curve). Although the humidity did not reach the optimal value for the growth of E. nuttallianus, the environmental humidity is much lower than that without fuzzy control. 


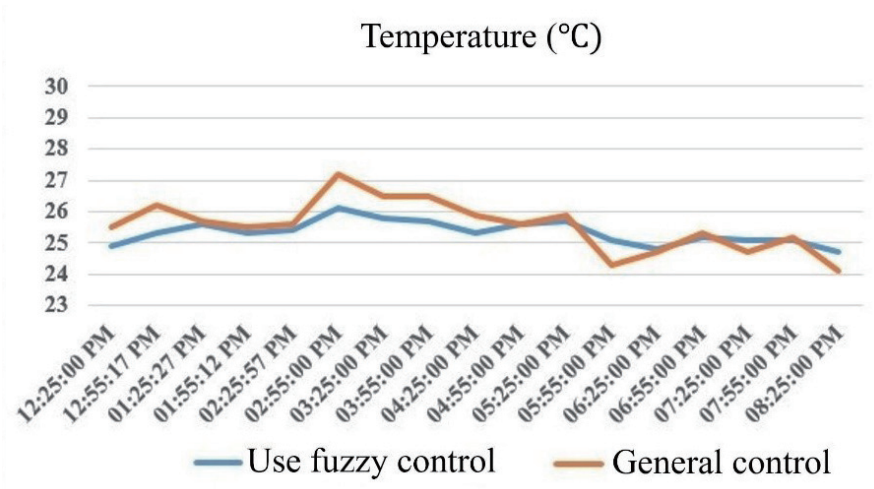

Fig. 20. (Color online) Line chart of temperature with and without fuzzy control.

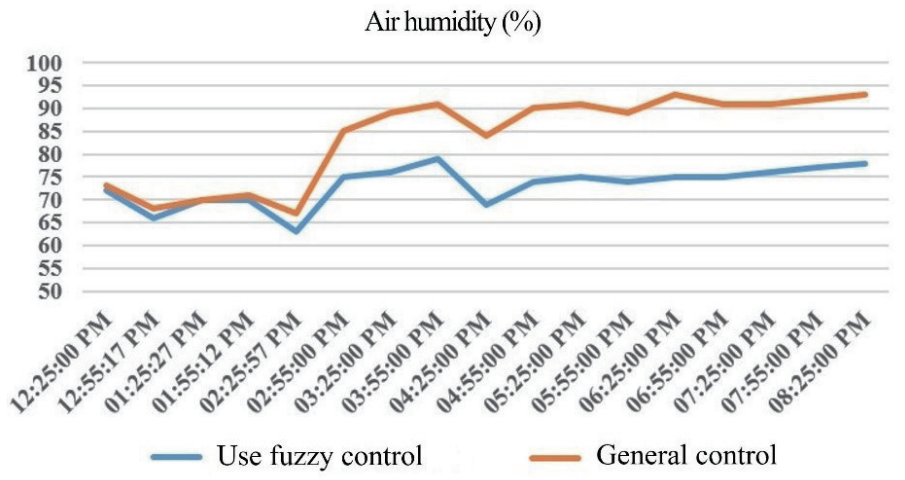

Fig. 21. (Color online) Line chart of humidity with and without fuzzy control.

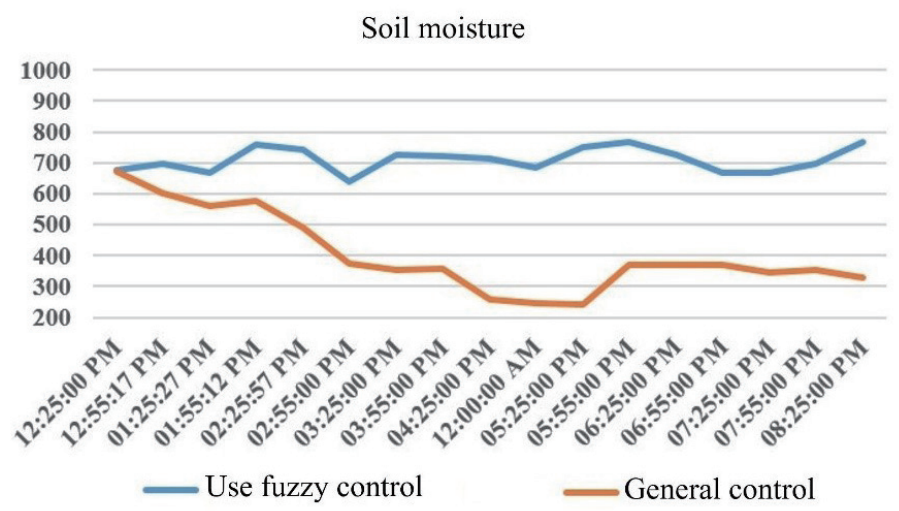

Fig. 22. (Color online) Line chart of soil dryness with and without fuzzy control.

The lower the soil dryness, the wetter the soil. The soil dryness should ideally fall between 600 and 800 . Because the pot is small in the experiment, the soil dryness changes more rapidly than in real-life situations. Without fuzzy control, the highest soil dryness is 672 , the lowest soil dryness is 243 , and the average soil dryness is 404.3 ; with fuzzy control, the highest soil dryness is 766 , the lowest soil dryness is 638 , and the average soil dryness is 709.2. It can be seen from Fig. 22 that the soil dryness with fuzzy control (blue curve) basically falls within the optimal range. 


\subsection{Sunny weather for many days}

Figure 23 shows the environmental values sensed when the weather was sunny for many consecutive days. From May 30 to June 5, 2020, the weather was sunny with no rain. The average temperature was $32{ }^{\circ} \mathrm{C}$. The main effect of sunny weather on plants is that the hightemperature environment accelerates evapotranspiration, which causes rapid loss of soil moisture.

By considering the 14:30 sensing data as an example, the temperature was determined to be $29.1{ }^{\circ} \mathrm{C}$, the humidity $73 \%$, and the soil dryness 898 , which means that the soil was very dry. The results of fuzzy inference are shown in Fig. 24. Because the air humidity and temperature only slightly exceeded the threshold values, the fan was not turned on. However, the soil moisture was very low, so the sprinkler was started, and because the temperature was very high and the humidity did not greatly exceed the threshold value, the plant lights were not turned on.

Without fuzzy control, the highest temperature is $31.5^{\circ} \mathrm{C}$, the lowest temperature is $27.9^{\circ} \mathrm{C}$, and the average temperature is $29.4{ }^{\circ} \mathrm{C}$. When fuzzy control is used, the highest temperature is $28.2{ }^{\circ} \mathrm{C}$, the lowest temperature is $25.6^{\circ} \mathrm{C}$, and the average temperature is $26.7^{\circ} \mathrm{C}$. It can be seen from Fig. 25 that the temperature with fuzzy control (blue curve) is lower and more in line with the optimum temperature for the growth of E. nuttallianus.

Without fuzzy control, the highest humidity is $77 \%$, the lowest humidity is $62 \%$, and the average humidity is $70.3 \%$. With fuzzy control, the highest humidity is $69 \%$, the lowest humidity is $59 \%$, and the average humidity is $64.6 \%$. In Fig. 26, it can be seen that air humidity with fuzzy control (blue curve) is more stable, less variable, and more in line with that for the optimal growth of E. nuttallianus.

Without fuzzy control, the highest soil dryness is 932 , the lowest soil dryness is 486 , and the average soil dryness is 761.1. With fuzzy control, the highest soil dryness is 796 and the lowest soil dryness is 674 . The average soil dryness is 733.7 . Without fuzzy control (orange curve in

\begin{tabular}{|c|c|c|c|c|c|c|}
\hline \multicolumn{9}{|c|}{ Use fuzzy control } & \multicolumn{5}{l|}{ General control } \\
\hline Time & Temp. $\left({ }^{\circ} \mathrm{C}\right)$ & Air humidity(\%) & Soil moisture & Temp. $\left({ }^{\circ} \mathrm{C}\right)$ & Air humidity $(\%)$ & Soil moisture \\
\hline $2020 / 6 / 210: 00$ & 27.1 & 67 & 767 & 28.7 & 72 & 764 \\
\hline $2020 / 6 / 210: 30$ & 27.1 & 66 & 759 & 28.3 & 74 & 763 \\
\cline { 2 - 7 } $2020 / 6 / 211: 00$ & 26.3 & 59 & 773 & 28.1 & 62 & 795 \\
\hline $2020 / 6 / 211: 30$ & 26.7 & 62 & 773 & 29.6 & 67 & 799 \\
\cline { 2 - 7 } $2020 / 6 / 212: 00$ & 27.3 & 60 & 689 & 30.1 & 65 & 823 \\
\hline $2020 / 6 / 212: 30$ & 27.5 & 63 & 674 & 31.2 & 69 & 809 \\
\hline $2020 / 6 / 213: 00$ & 28.2 & 63 & 682 & 31.5 & 69 & 844 \\
\hline $2020 / 6 / 213: 30$ & 27.7 & 61 & 684 & 30.7 & 67 & 887 \\
\hline $2020 / 6 / 214: 00$ & 26.8 & 61 & 708 & 29.8 & 69 & 887 \\
\hline $2020 / 6 / 214: 30$ & 26.4 & 67 & 723 & 29.1 & 73 & 898 \\
\hline $2020 / 6 / 215: 00$ & 25.9 & 65 & 796 & 27.9 & 68 & 921 \\
\hline $2020 / 6 / 215: 30$ & 25.6 & 69 & 746 & 27.9 & 76 & 932 \\
\hline $2020 / 6 / 216: 00$ & 26.3 & 69 & 683 & 28.6 & 77 & 486 \\
\hline $2020 / 6 / 216: 30$ & 26.7 & 66 & 717 & 29.2 & 69 & 488 \\
\hline $2020 / 6 / 217: 00$ & 26.7 & 66 & 758 & 30.6 & 74 & 512 \\
\hline $2020 / 6 / 217: 30$ & 26.9 & 65 & 762 & 28.9 & 68 & 638 \\
\hline $2020 / 6 / 218: 00$ & 25.8 & 69 & 779 & 28.7 & 76 & 674 \\
\hline
\end{tabular}

Fig. 23. (Color online) Environmental data with and without fuzzy control. 


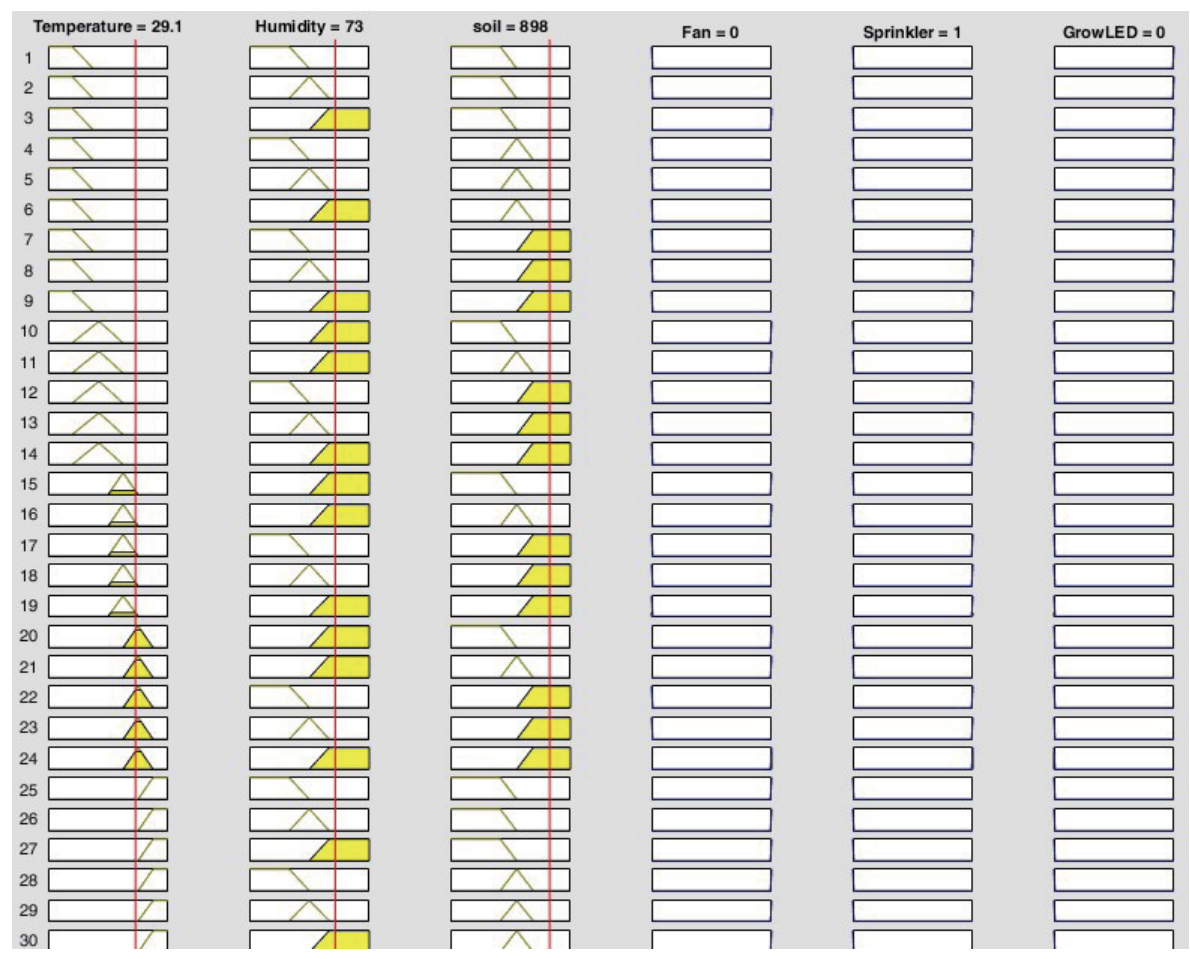

Fig. 24. (Color online) Results of fuzzy inference of data of 2020/6/2 14:30.

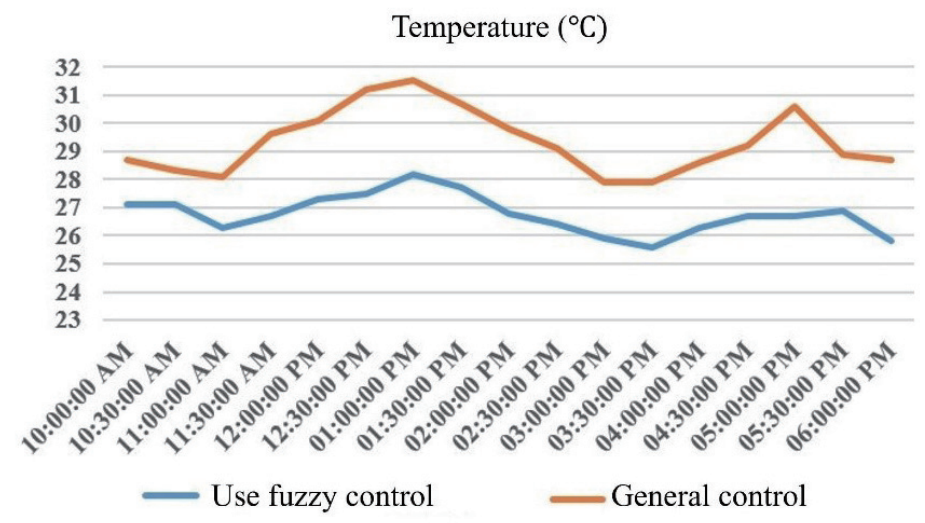

Fig. 25. (Color online) Line chart of temperature with and without fuzzy control.

Fig. 27), a sudden drop in soil dryness was observed because the sprinkler was turned on at 4 p.m. Moreover, the soil moisture with fuzzy control (blue curve) fell within the optimal soil dryness range.

\subsection{Comparison of plant appearance in experiments}

In Fig. 28, the blue star plant grown with fuzzy control is on the left. With the fans, plant lights, and sprinklers controlled automatically by fuzzy control, the branches and leaves are more luxuriant, the number of flowers is large, and the flowering state is relatively stable and 


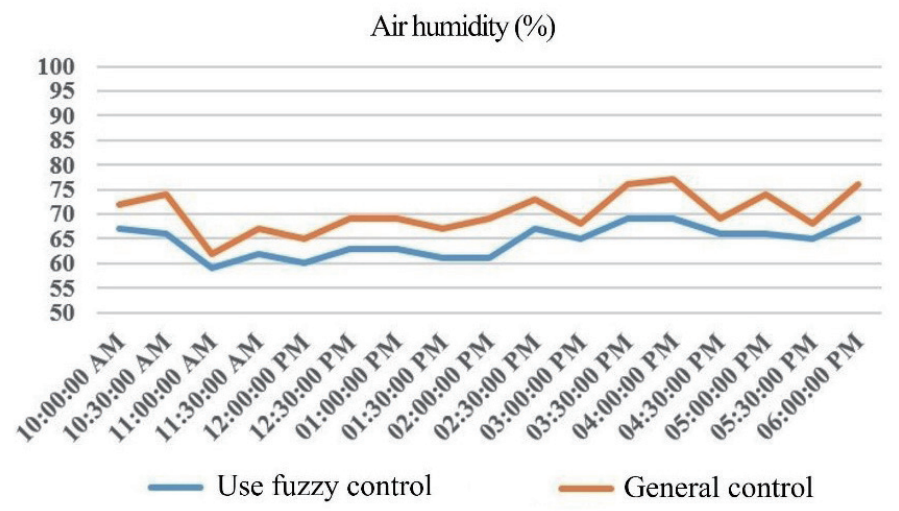

Fig. 26. (Color online) Line chart of humidity with and without fuzzy control.

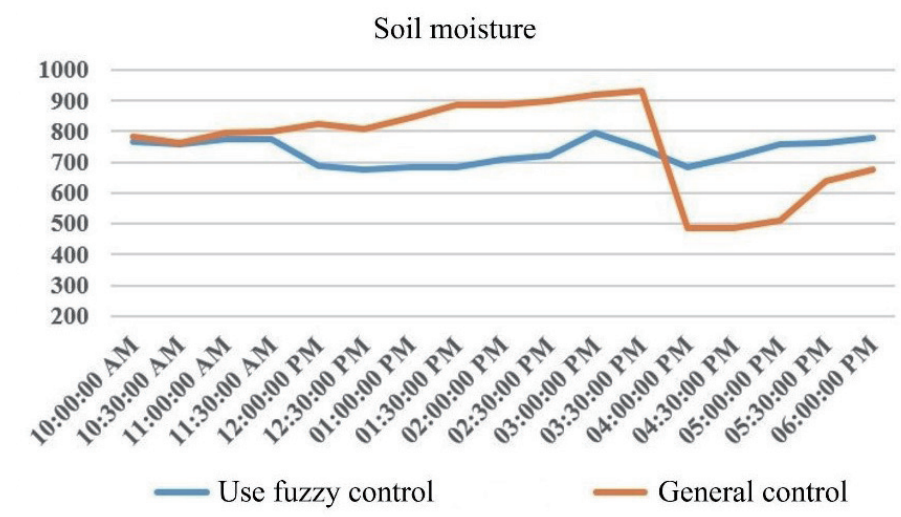

Fig. 27. (Color online) Line chart of soil dryness with and without fuzzy control.

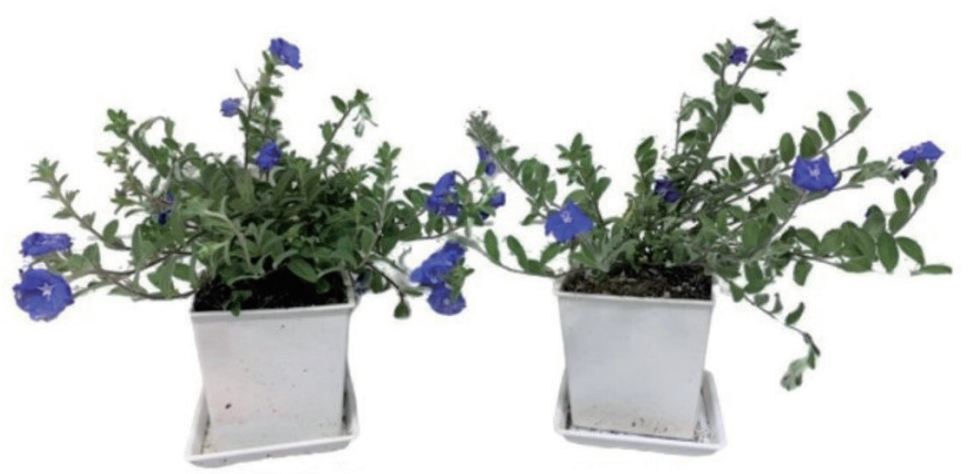

Fig. 28. (Color online) Blue star plants grown with and without fuzzy control.

dense. On the right is the blue star plant grown without fuzzy control. Water was given manually during work hours, and the air temperature and humidity were not specially controlled. The branches and leaves are relatively sparse, the number of flowers is small, the flowering state is unstable, and the branches of the plant grow haphazardly. 
Figure 29(a) shows the soil condition of E. nuttallianus grown with fuzzy control. Because the sprinkler is automatically controlled to keep the soil moisture in a suitable range, the soil is moist. The blue star plant without fuzzy control in Fig. 29(b) has dry soil because office workers generally watered the plant during work hours, and there was no other watering outside work hours.

In Fig. 30(a), the leaves of the blue star plant grown with fuzzy control have a brighter color and are erect and healthy. In Fig. 30(b), the blue star plant without fuzzy control has darker leaves that are curled owing to lack of water.

In Fig. 31(a), the petals of E. nuttallianus grown with fuzzy control are brighter in color and full and elastic. Figure 31(b) shows that E. nuttallianus without fuzzy control has duller petals that are also damaged and dry.

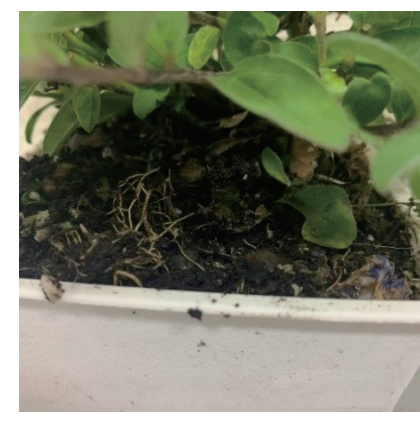

(a)

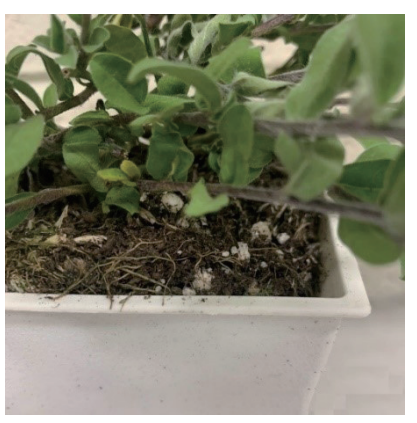

(b)

Fig. 29. (Color online) Soil condition of blue star plants grown (a) with and (b) without fuzzy control.

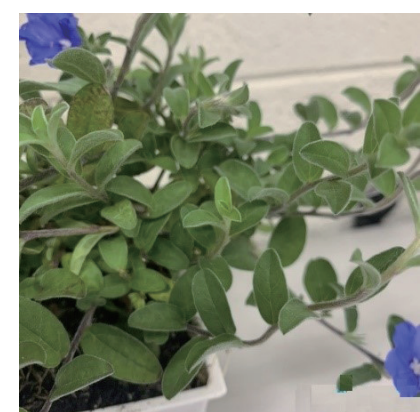

(a)

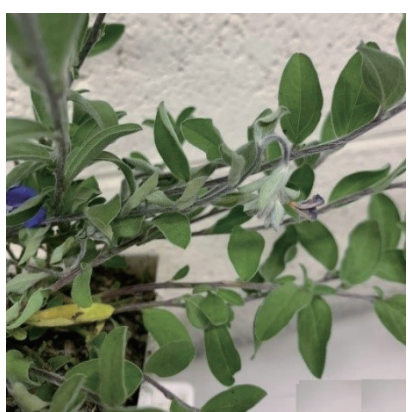

(b)

Fig. 30. (Color online) Leaves of blue star plants grown (a) with and (b) without fuzzy control.

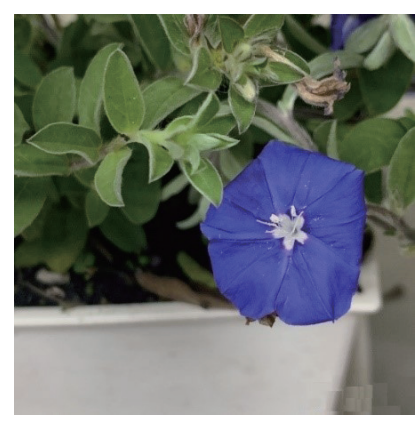

(a)

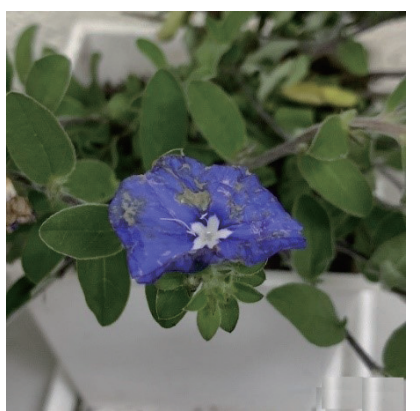

(b)

Fig. 31. (Color online) Petals of E. nuttallianus grown (a) with and (b) without fuzzy control. 


\subsection{Monitoring interface of system connected to cloud}

This research is based on the concept of the wireless transmission of the IoT. The data sensed by the sensing module is transmitted to the ThingSpeak platform through the ESP8266 Wi-Fi chip in NodeMCU. Line graphs of the platform data are shown in Fig. 32. The mobile application can also read the values of the graphs in the ThingSpeak platform and display them on the user interface, as shown in Fig. 33. As long as the user is connected to the Internet, the environment of the user's courtyard can be examined anytime. Past data can be downloaded for analysis, as shown in Fig. 34, and the control mode can be switched from automatic to manual via a mobile phone application to remotely control the switches of various loads in the courtyard.

Figure 35 shows the main interface of the mobile phone application, which displays the temperature, air humidity, soil status, light, and weather conditions of the courtyard. Upon pressing the yellow Manual Control button in the interface to switch to the manual mode, as

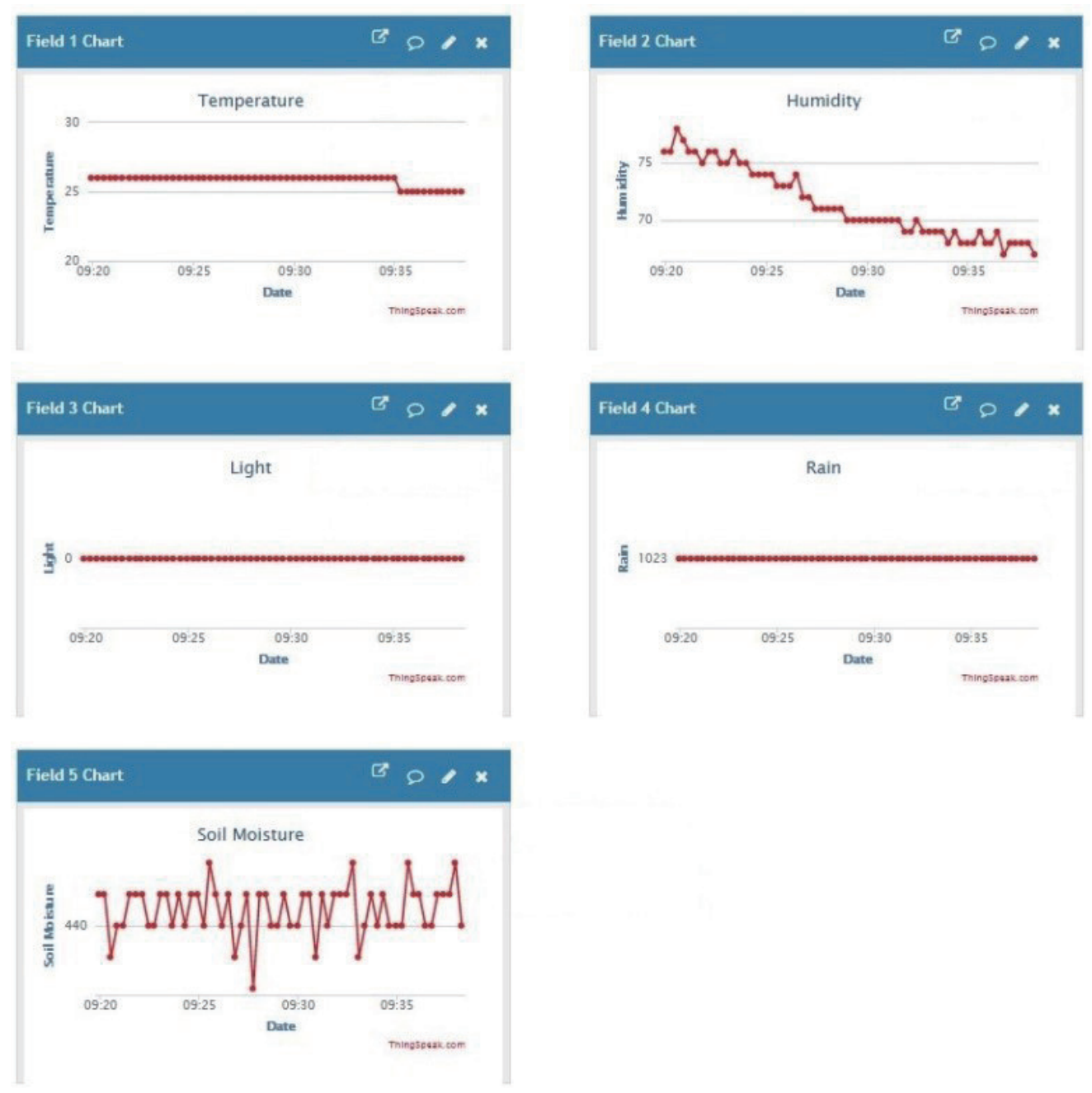

Fig. 32. (Color online) Line graphs of ThingSpeak platform data. 


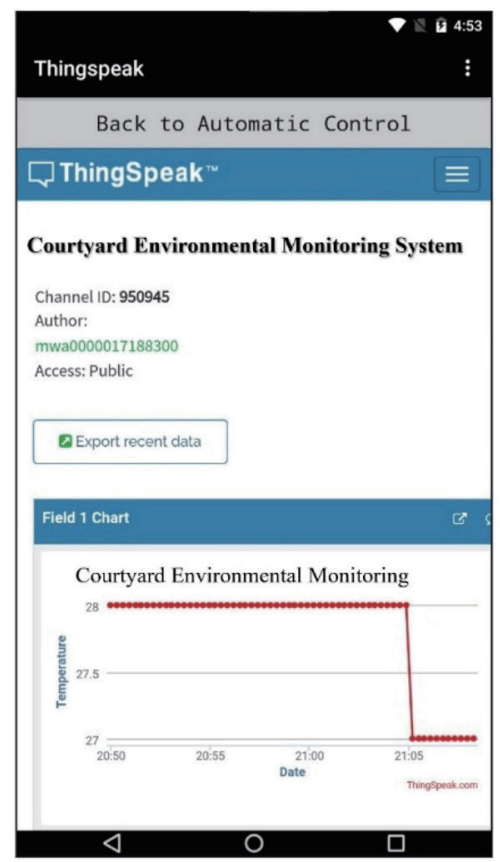

Fig. 33. (Color online) Interface of ThingSpeak platform using mobile app.

\section{$\square$ ThingSpeak ${ }^{m}$ Channels- Apps - Support- Commercial Use How to Buy HL}

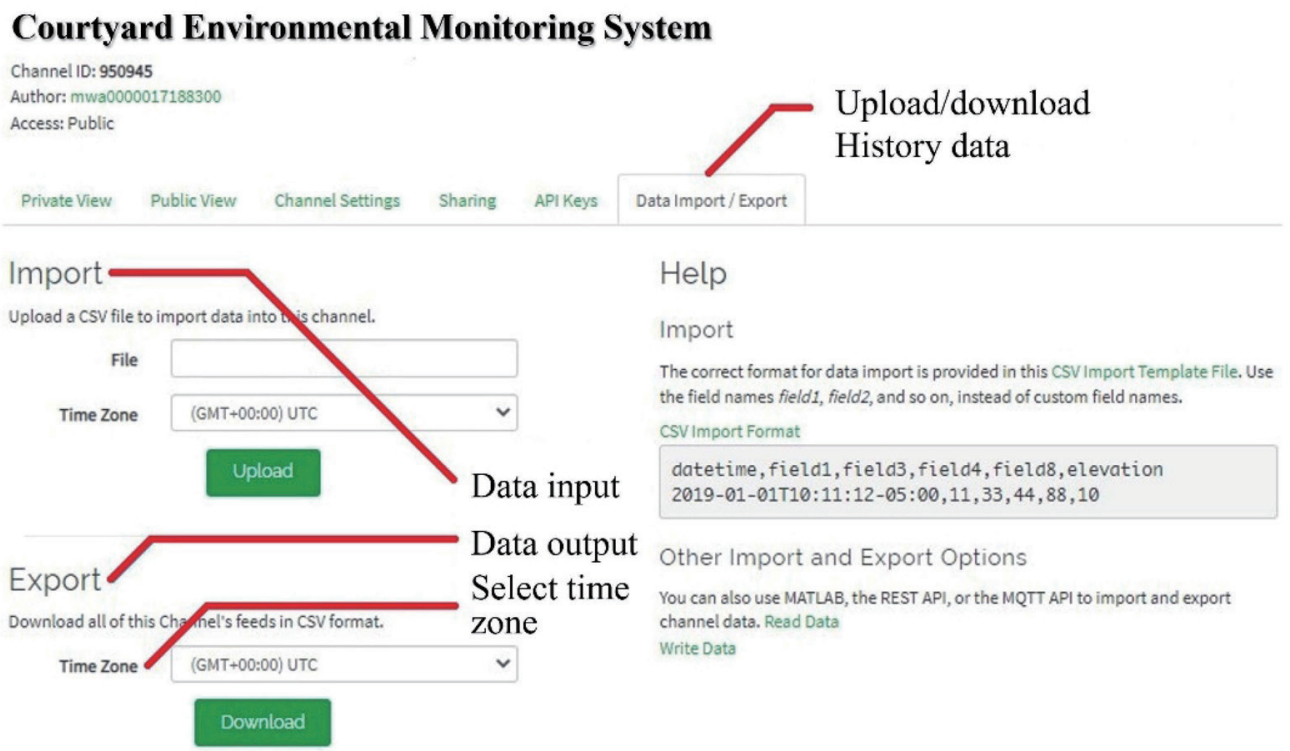

Fig. 34. (Color online) ThingSpeak platform data download/upload interface.

shown in Fig. 36, the manual mode interface of the mobile phone application is shown. The gray Show ThingSpeak button in the interface is pressed to go directly to the ThingSpeak platform interface via the mobile app to view the line graphs of environmental data, as shown in Fig. 33. 


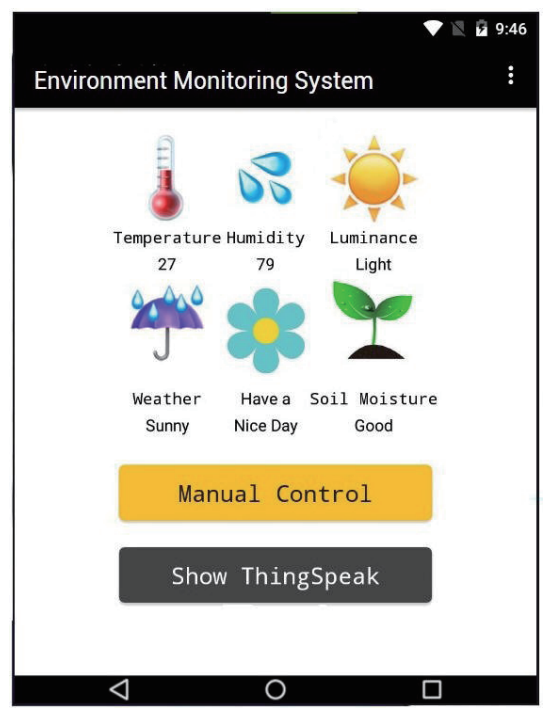

Fig. 35. (Color online) Main interface of mobile phone application.

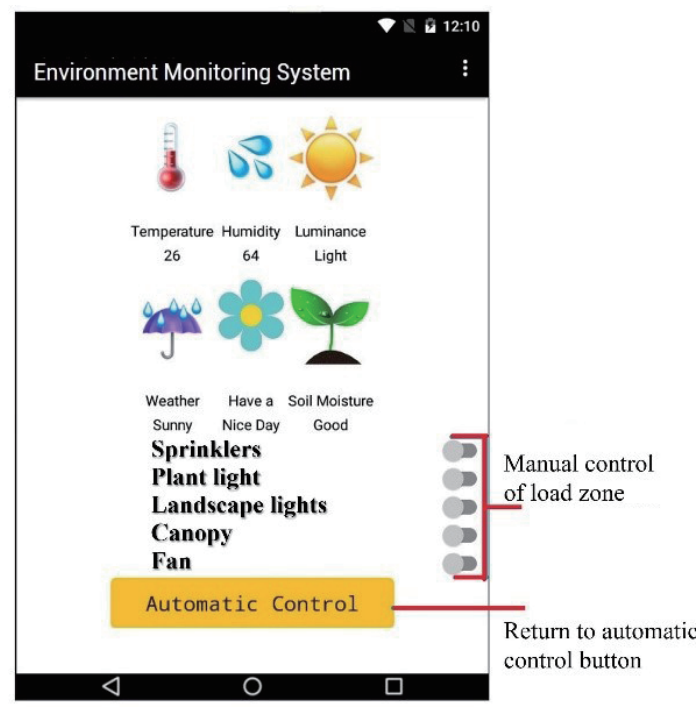

Fig. 36. (Color online) Manual mode interface of mobile phone application.

\section{Conclusions}

For people who live a busy life, are unfamiliar with gardening, are eager to relieve the stress of life through plants, or love plants but have limited mobility, our system can reduce the time and energy required to care for plants while ensuring that plants grow in a healthy environment. The system implements the concepts of wireless transmission and remote control through the interconnected structure of the IoT.

Using NodeMCU as the control board, with the wireless transmission of signals via the ESP8266 Wi-Fi chip, the integration of four sensing modules and five loads, and the wireless transmission of sensed ambient values to the ThingSpeak platform and storage, users can monitor the courtyard environment in real time from any device with Internet access to the platform or mobile phone application, as well as switch to the manual mode in the mobile phone application to remotely control the load.

The system uses fuzzy algorithms to analyze the temperature, air humidity, and soil moisture in the courtyard, updates environmental values every $30 \mathrm{~min}$, establishes a rule bank based on ideal living conditions of the plant under test, and automatically controls the movement of sprinklers, fans, and plant lights. When light is not sensed, the landscape light is turned on, when the raindrop sensing module senses raindrops, the step motor rolls out the shelter, and when the rain stops, the step motor reverses and retracts the shelter. The above automatic control keeps the courtyard environmental parameters at appropriate values. Compared with uncontrolled plant care, the environmental values of plant care using fuzzy control are more suitable for plant growth.

In the future, the proposed research can be combined with image identification and applied to yard safety monitoring to detect intruders. When the system is applied to courtyard plants or to a 
small farm, the color changes of the leaves or the health status of the branches can be used to judge the health of the plants or crop, and warning messages can be transmitted in real time to the monitor.

\section{Acknowledgments}

This research was supported by the Department of Electrical Engineering at National Chin-Yi University of Technology. The authors would like to thank National Chin-Yi University of Technology, Takming University of Science and Technology, Taiwan, for supporting this research.

\section{References}

1 D. Zhu, M. Shafique, M. Lin, and S. Pasricha: IEEE Trans. Sustainable Comput. 3 (2018) 137. https://doi. org/10.1109/TSUSC.2018.2813078

2 S. Javaid, H. Afzal, F. Arif, and N. Iltaf: Proc. 2018 20th Int. Conf. Advanced Communication Technology (2018) 1. https://doi.org/10.23919/ICACT.2018.8323767

3 A. Saifullah, Y. Xu, C. Lu, and Y. Chen: IEEE Trans. Comput. 64 (2015) 1361. https://doi.org/10.1109/ TC.2014.2322609

4 M. Sampaio, A. L. G. Modesto, E. G. de Almeida Sobrinho, J. F. Almeida, and O. A. Chase: IEEE Latin America Trans. 12 (2014) 1404. https://doi.org/10.1109/TLA.2014.7014507

5 M. Manso-Vázquez and M. Llamas-Nistal: IEEE Revista Iberoamericana de Tecnologias del Aprendizaje. 10 (2015) 52. https://doi.org/10.1109/RITA.2015.2417952

6 A. K. Gupta and R. Johari: Proc. 2019 4th Int. Conf. Internet of Things: Smart Innovation and Usages (2019) 1-5. https://doi.org/10.1109/IoT-SIU.2019.8777342

7 S. K. Vishwakarma, P. Upadhyaya, B. Kumari, and A. K. Mishra: Proc. 2019 4th Int. Conf. Internet of Things: Smart Innovation and Usages (2019) 1-4. https://doi.org/10.1109/IoT-SIU.2019.8777607

8 E. P. Yadav, E. A. Mittal, and H. Yadav: Proc. 2018 3rd Int. Conf. Internet of Things: Smart Innovation and Usages (2018) 1-5. https://doi.org/10.1109/IoT-SIU.2018.8519869

9 S. Saloni and A. Hegde: Proc. 2016 Int. Conf. Internet of Things and Applications (2016) 137-142. https://doi. org/10.1109/IOTA.2016.7562710

10 S. Huang, L. Li, H. Cai, B. Xu, G. Li, and L. Jiang: IEEE Trans. Syst. Man Cybern. Syst. 49 (2019) 123. https:// doi.org/10.1109/TSMC.2017.2753465

11 N. Sahni, J. Bose, and K. Das: Proc. 2018 Int. Conf. Advances in Comput. Communications and Informatics (2018) 2175-2181. https://doi.org/10.1109/ICACCI.2018.8554612

12 B. Klotz, S. K. Datta, D. Wilms, R. Troncy, and C. Bonnet: Proc. 2018 Global Internet of Things Summit (2018) 1-6. https://doi.org/10.1109/GIOTS.2018.8534533

13 S. K. Datta and C. Bonnet: Proc. 2018 IEEE Int. Conf. Consumer Electronics-Taiwan (2018) 1-2. https://doi. org/10.1109/ICCE-China.2018.8448890

14 S. K. Datta, M. Irfan Khan, L. Codeca, B. Denis, J. Härri, and C. Bonnet: Proc. 2018 IEEE 19th Int. Symp. 'A World of Wireless, Mobile and Multimedia Networks' (2018) 14-19. https://doi.org/10.1109/ WoWMoM.2018.8449768

15 S. Javaid, H. Afzal, F. Arif, and N. Iltaf: Proc. 2018 20th Int. Conf. Advanced Communication Technology (2018) 1. https://doi.org/10.23919/ICACT.2018.8323767

16 B. C. B. Solomon and S. M. Aral: Proc.2017 Third Int. Conf. Science Technology Engineering \& Management (2017) 429-431. https://doi.org/10.1109/ICONSTEM.2017.8261422 


\section{About the Authors}

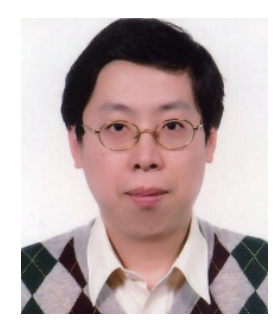

Wen-Tsai Sung is working in the Department of Electrical Engineering, National Chin-Yi University of Technology, as a distinguished professor and dean of research and development. He received his M.S. and Ph.D. degrees from the Department of Electrical Engineering, National Central University, Taiwan, in 2000 and 2007, respectively. He won the 2009 JMBE Best Annual Excellent Paper Award and the Dragon Thesis Award sponsored by Acer Foundation. His research interests include artificial intelligence IoT (AIoT) and wireless sensor networks. (songchen@ncut.edu.tw)

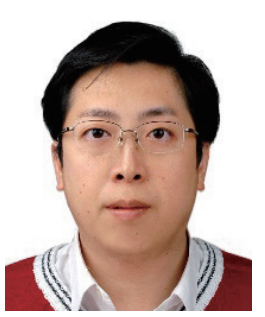

Sung-Jung Hsiao is working in the Department of Information Technology, Takming University of Science and Technology, as an assistant professor. He received his B.S. degree in electrical engineering from National Taipei University of Technology, Taiwan, in 1996, his M.S. degree in computer science and information engineering from National Central University, Taiwan, in 2003, and his Ph.D. degree from the Department of Electrical Engineering, National Taipei University of Technology, in 2014. He has acquired experience in research and design at Acer Universal Computer Co., Mitsubishi, and FIC. (sungjung@gs.takming.edu.tw) 